\title{
High-temperature $\mathrm{CO} / \mathrm{HC}$ gas sensors to optimize firewood combustion in low-power fireplaces
}

\author{
Binayak Ojha, Navas Illyaskutty, Jens Knoblauch, Muthu Raman Balachandran, and Heinz Kohler \\ Institute for Sensor and Information Systems (ISIS), Karlsruhe University of Applied Sciences, \\ 76133 Karlsruhe, Germany \\ Correspondence to: Heinz Kohler (heinz.kohler@hs-karlsruhe.de)
}

Received: 30 September 2016 - Revised: 27 January 2017 - Accepted: 31 March 2017 - Published: 14 June 2017

\begin{abstract}
In order to optimize firewood combustion in low-power firewood-fuelled fireplaces, a novel combustion airstream control concept based on the signals of in situ sensors for combustion temperature, residual oxygen concentration and residual un-combusted or partly combusted pyrolysis gas components (CO and $\mathrm{HC}$ ) has been introduced. A comparison of firing experiments with hand-driven and automated airstream-controlled furnaces of the same type showed that the average $\mathrm{CO}$ emissions in the high-temperature phase of the batch combustion can be reduced by about $80 \%$ with the new control concept. Further, the performance of different types of high-temperature $\mathrm{CO} / \mathrm{HC}$ sensors (mixed-potential and metal oxide types), with reference to simultaneous exhaust gas analysis by a high-temperature FTIR analysis system, was investigated over 20 batch firing experiments $(\sim 80 \mathrm{~h}$ ). The distinctive sensing behaviour with respect to the characteristically varying flue gas composition over a batch firing process is discussed. The calculation of the Pearson correlation coefficients reveals that mixed-potential sensor signals correlate more with $\mathrm{CO}$ and $\mathrm{CH}_{4}$; however, different metal oxide sensitive layers correlate with different gas species: $1 \% \mathrm{Pt} / \mathrm{SnO}_{2}$ designates the presence of $\mathrm{CO}$ and $2 \% \mathrm{ZnO} / \mathrm{SnO}_{2}$ designates the presence of hydrocarbons. In the case of a TGS823 sensor element, there was no specific correlation with one of the flue gas components observed. The stability of the sensor signals was evaluated through repeated exposure to mixtures of $\mathrm{CO}, \mathrm{N}_{2}$ and synthetic air after certain numbers of firing experiments and exhibited diverse long-term signal instabilities.
\end{abstract}

\section{Introduction}

Residential wood combustion is of widespread concern owing to its sustainable nature as a source of heat energy as well as its adverse impacts on air quality and human health. Particularly in many developing countries, wood is regularly used for residential cooking and heating. However, developed countries have also identified wood as a cheap alternative for domestic heating, mainly in the countryside. In Germany, about 14 million low-power $(<15 \mathrm{~kW})$, single-room, firewood-fuelled fireplaces and about 1 million firewoodfuelled central heaters are being operated (Lenz and Thrän, 2015). Even after the second grade of the new German emission law (the first BImSchV) for firewood-fuelled low-power fireplaces came into effect in 2015, the upper emission limits for firewood-fuelled single-room fireplaces $\left(1250 \mathrm{mg} \mathrm{m}^{-3}\right.$ for $\mathrm{CO}$ and $40 \mathrm{mg} \mathrm{m}^{-3}$ for particulate matter; $\mathrm{PM}$ ) and cen- tral heaters ( $400 \mathrm{mg} \mathrm{m}^{-3}$ for $\mathrm{CO}$ and $20 \mathrm{mg} \mathrm{m}^{-3}$ for PM) are still specified higher than the typical emissions from heating oil burners (about $50 \mathrm{mg} \mathrm{m}^{-3} \mathrm{CO}$ ).

Under ideal conditions, i.e. with perfect admixing of the flue gas with a stoichiometric amount of air and a reaction rate that would be fast enough, the complete combustion of wood or biomass would result solely in the emission of water vapour, carbon dioxide $\left(\mathrm{CO}_{2}\right)$ and inorganic PM. However, these ideal process conditions cannot be achieved in conventional firewood-fuelled low-power fireplaces. It was demonstrated that in addition to $\mathrm{CO}_{2}$ and water, incomplete combustion conditions result in the emission of numerous gaseous species like $\mathrm{CO}$, methane, aldehydes, alcohols, organic acids, partially oxidized hydrocarbons (HCs), polycyclic aromatic hydrocarbons (PAHs) and aerosolized compounds (Tapanainen et al., 2011; Jalava et al., 2010). 
Gaseous components with high boiling points are found in large amounts in condensed form (loaded on PM), and their high cytotoxic potential was identified by in vitro cell death studies using co-cultures of macrophages and respiratory epithelial cells (Tapanainen et al., 2011; Jalava et al., 2010). In this context, it is of essential importance to improve the quality of firewood combustion for the reduction of such toxic emissions.

The important parameters which estimate the quality of firewood combustion are the combustion temperature (Tc), the amount of supplied air at the combustion chambers, the admixing of combustion air with the flue gas and the retention time of the gas mixture in the post-combustion chamber (Nussbaumer, 2003; Tissari et al., 2008). The first and the last two parameters are considerably influenced by the construction quality of the fireplaces (Meyer, 2012). For complete combustion over a whole batch of combustion processes, the reaction kinetics for the complete oxidation of the flue gas components should be high enough, i.e. at temperatures higher than $\sim 700^{\circ} \mathrm{C}$, provided that the retention time in the post-combustion chamber is long enough (Butschbach et al., 2009). This means that in a batch firing process, complete combustion is possible only in the high-temperature (HT) combustion phase which follows the ignition phase (IP) and ends with a transition to the burnout phase (BOP). Both the IP and the BOP are phases of lower temperatures; therefore, the highest emissions of toxic gases and PM loaded with condensed organics are expected. To reduce the toxic emissions, the low temperature phases (IP and BOP) of a batch firing should be kept as short as possible by providing an optimal amount of combustion air at every moment of the combustion process. This requires the implementation of proper automated and optimized combustion airstream control strategies. Further, an improvement in combustion quality can be achieved with catalytic support to the post-combustion process, even in the phases of lower combustion temperatures (Butschbach et al., 2009). It was reported that operational conditions, like the ignition technique (upside-down or bottom-up), fuel type and use of split or non-split firewood, also have a strong influence on the combustion quality (Vicente et al., 2015).

The control of the airstreams based on the Tc and the residual oxygen concentration (ROC) in the flue gas is the current state of the art. However, our previous investigations conducted at various fireplaces (Butschbach et al., 2009; Kohler et al., 2010) have shown that for the efficient operation of low-power fireplaces, it is not only essential to enable sufficient combustion air but also to avoid cooling effects in the post-combustion chamber by supplying excess air throughout the firing process. This means that the proper adjustment of the combustion air has to be defined by separate control of the airstreams into the primary and post-combustion chambers and cannot be based solely on Tc and ROC (this strategy is commonly adopted in gasoline- and diesel-fuelled combustion engines) due to the incomplete admixing of the

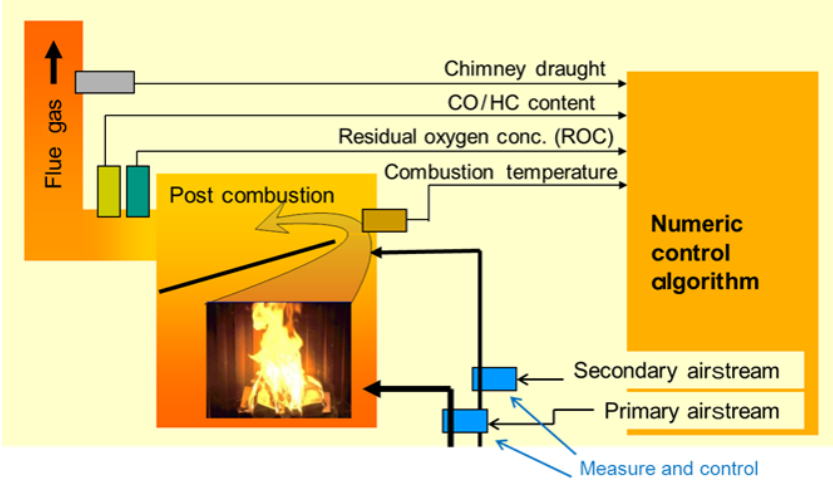

Figure 1. A schematic representation of an automated airstreamcontrolled wood combustion system.

pyrolysis gases with injected air. These aspects indicate the necessity of a representative knowledge of the combustion situation at every moment of the firing process by monitoring the actual content of $\mathrm{CO} / \mathrm{HC}$ in the flue gas in addition to Tc and ROC (Kohler et al., 2010, 2013) and making use of these parameters for controlling the airstreams. However, the suitability of a $\mathrm{CO} / \mathrm{HC}$ sensor for in situ application in the exhaust gases from firewood combustion processes is not well investigated. High-temperature gas sensors using mixed-potential electrochemical cells based on yttrium-stabilized zirconium oxide (Butschbach et al., 2009), chemoresistive metal oxide sensors (Eskilsson et al., 2004; Illyaskutty et al., 2015), SiC-based field effect transistors (Andersson et al., 2013) and, perhaps, thermoelectric hydrocarbon sensors (Wiegärtner et al., 2015) are reported to be possible candidates for these applications.

In the first part of this work, we exemplify the advantage of having an automated airstream control system for lowpower fireplaces. A schematic representation of such an automated airstream-controlled system is illustrated in Fig. 1. This is accomplished by comparing the results of an automated firing experiment on a log-fuelled single-room heating furnace with those conducted in a hand-controlled furnace of the same type operated according to the instructions given by the manufacturer. The experimental details related to the aspects of the reproducibility of these experiments and to the concepts of airstream control are reported elsewhere (Butschbach et al., 2009; Kohler et al., 2013). The second and main part is directed toward an investigation of the characteristic performance of different types of $\mathrm{CO} / \mathrm{HC}$ sensors, specifically mixed-potential (MP) and metal oxide (MO) gas sensors, suitable for high-temperature applications in the flue gas. This was motivated by the fact that although the high efficiency of automated airstream control algorithms for lowpower wood combustion processes based on gas sensors, including continuous $\mathrm{CO} / \mathrm{HC}$ analysis, was clearly reported in the past (Butschbach et al., 2009; Kohler et al., 2010), suitable and long-term stable sensor elements for continuous in 

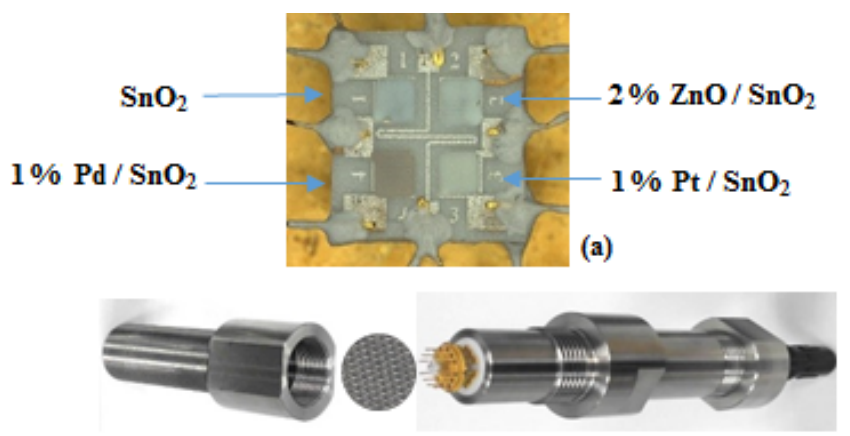

(b)

Figure 2. The MO sensor array (a) and housing (b). A special flange was designed for the adaptation of the sensor to the exhaust gas tube and the separation of the sensor element with a filter for protection against PM and soot particles.

situ $\mathrm{CO} / \mathrm{HC}$ monitoring at harsh exhaust gas conditions are still not available. These $\mathrm{CO} / \mathrm{HC}$ sensors are validated to assess their long-term stability and also their individual (cross-) sensitivities to the varying compositions of the flue gas components at different phases of the batch firing process. Furthermore, the suitability of these kinds of sensor signals for the proper control of the combustion airstreams is discussed.

\section{Sensors under investigation}

Various types of sensors are operated in the exhaust gas tube of the firewood-fuelled fireplace. These include the commercially available MP CarboSen $1 \mathrm{~K}(\mathrm{CS} 1 \mathrm{~K})$ and CarboSen $10 \mathrm{~K}$ (CS10K; Lamtec Meß- und Regeltechnik für Feuerungen GmbH \& Co. KG, Walldorf, Germany), an indigenously developed MO sensor array (Fig. 2) and a commercially available MO gas sensor TGS823 (Figaro Engineering Inc., Osaka, Japan).

CS1K and CS10K are non-Nernstian MP gas sensors sintered at different temperatures, 850 and $1050{ }^{\circ} \mathrm{C}$, respectively, during the fabrication process (Zhang et al., 2015). Both have a planar structure with a solid-state electrochemical cell on one side of an $\mathrm{Al}_{2} \mathrm{O}_{3}$ substrate formed by a $\mathrm{Pt}$ reference electrode integrated under a porous stabilized zirconium oxide (8YSZ) solid electrolyte layer and two identical Pt / Au-sensitive electrodes on top, and a platinum heater covered by a passivation layer on the reverse side. The details of the structure of the Au/Pt electrode are published elsewhere (Zhang et al., 2015). In the presence of oxidizable gases, an MP is formed at the sensing electrode, whereas a typical Nernstian half-cell potential is formed at the reference electrode representing the ROC in thermodynamic equilibrium with all combustible components. The details of the theoretical functionality of this kind of sensor are well described in Miura et al. (2014). The output signal of the sensor is the potential difference $(U)$ between the sensing electrode and the reference electrode and is a logarithmic function of the gas concentration $c_{i}$ of gas component $i$ and of the ROC $c\left(\mathrm{O}_{2}\right)$ according to Eq. (1):

$U=\alpha_{i}-\beta_{i} \ln \left(c_{i}\right)+\gamma_{i} \ln \left(c\left(\mathrm{O}_{2}\right)\right)$.

Here, $\alpha_{i}$ depends on the reference half-cell and is approximately constant if the combustion process is operated at oxygen excess conditions but depends on temperature as well as the constants $\beta_{i}$ and $\gamma_{i}$. All molecules involved in the MP formation process, together with adsorbed oxygen, contribute to the sensor signal $U$ (Moos et al., 2009). This means that the sensor signal depends in a complicated way on all reactive gas components with different sensitivities, which is further influenced by temperature and electrode material (Miura et al., 2014).

The resistive MO sensor array, which is fabricated in our labs using thin-film and thick-film technologies, is comprised of four microdispensed, thick-film, metal-oxide-sensitive layers of different $\mathrm{SnO}_{2}$ additives (pure $\mathrm{SnO}_{2}, 2 \% \mathrm{ZnO}, 1 \%$ $\mathrm{Pt}$ and $1 \% \mathrm{Pd}$ ) on Pt-interdigitated electrodes on the top side of an $\mathrm{Al}_{2} \mathrm{O}_{3}$ substrate and a thin-film Pt heater microstructured on the reverse side (Fig. 2). A detailed description of the sensor fabrication process is given in Frank et al. (2008) and Knoblauch et al. (2015). It is operated in the flue gas at $450{ }^{\circ} \mathrm{C}$, and the operating temperature is controlled by a resistive thin-film temperature sensor integrated at the upper side of the chip. For a comparison of the performance with a commercially available MO sensor, a TGS823, which was specifically designed for the detection of organic vapours, is simultaneously operated in the flue gas.

The output signal of the MO sensors is the change in the sensitive layer conductance $(G)$ due to the surface gas reaction processes of the target gas components $i$ with adsorbed oxygen states $\left(\mathrm{O}_{\mathrm{ads}}^{-}, \mathrm{O}_{2 \mathrm{ads}}^{-}\right)$. These types of sensors respond to different oxidizable and reducible gas components with different sensitivities, dependent on the type of $\mathrm{MO}\left(\mathrm{SnO}_{2}\right.$, $\mathrm{ZnO}, \mathrm{WO}_{3}$ ), the kind of (catalytically active) additives (e.g. $\mathrm{Pt}, \mathrm{Pd}, \mathrm{CuO}, \mathrm{ZnO}$ ) and the operation temperature. The theoretical models of the gas-sensing mechanism have been described already in Morrison (1987) and are still a matter of discussion (Wang et al., 2010). The oxygen in the gas atmosphere equilibrates with the oxygen defects in the bulk (slow process) and with the oxygen surface states (quick process), which results in oxygen cross-sensitivities in the signal. In addition, most of these sensors are cross-sensitive to water vapour (Kohl, 1989; Hahn et al., 2003). In general, the conductance change $\Delta \mathrm{G}$ relates to the concentration of an individual gas component $c_{i}$ according to Eq. (2) (Comini et al., 2009):

$\Delta G=\alpha_{i} \cdot c_{i}^{\beta_{i}}$,

where $\alpha_{i}$ and $\beta_{i}$ are parameters depending on the individual gas component $i$. 


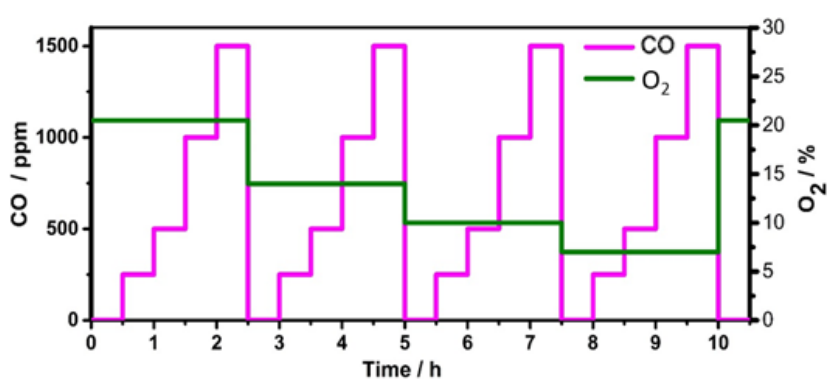

Figure 3. The gas exposure sequence over time for the sensitivity measurements of the $\mathrm{CO} / \mathrm{HC}$ sensors. The sensors are exposed to 250, 500, 1000 and $1500 \mathrm{ppm}$ of $\mathrm{CO}$ at a 20.5, 14, 10.5 and $7 \%$ oxygen concentration.

\section{Experimental design}

\subsection{Sensor calibration and long-term stability tests}

$\mathrm{CO}$ is the leading gas component in the flue gas of wood combustion processes, and its concentration varies continuously and characteristically over a batch firing process. Moreover, the ROC is also observed to be varied between 5 and $21 \%$. Because the emissions and the combustion situation are not easily reproducible, it is extremely difficult to estimate the sensor signal stability from firing experiments alone. Hence, to get a better understanding of the individual sensitivities and the signal stability of the aforementioned sensors, each sensor was calibrated in mixtures of $\mathrm{CO}, \mathrm{N}_{2}$ and synthetic air at different oxygen concentrations according to the gas exposure scheme shown in Fig. 3. This was done before and between a series of firing experiments using the automated gas mixing set-up described in Jerger et al. (2002). However, these model gas mixtures do not represent the real exhaust gas composition, which can be composed of more than 40 different components at different concentrations (Marutzky et al., 1999). Accordingly, the sensor signal of these MP and chemoresistive MO gas sensor elements is estimated by more or less all reactive gas components of the flue gas with individual sensitivities and therefore can only roughly represent the flue gas composition as a COequivalent $\left(\mathrm{CO}_{\mathrm{e}}\right)$ value (Butschbach et al., 2009). These calibrated $\mathrm{CO}_{\mathrm{e}}$ values of the MP gas-sensing elements are used as a $\mathrm{CO} / \mathrm{HC}$ input parameter for the combustion airstream control algorithm (Sect. 3.2).

\subsection{Installation of fireplaces and operation}

The efficacy of the firing process control concept was validated by conducting experiments with two low-power furnaces (Varia 2R; Spartherm GmbH, Melle, Germany; Fig. 4a) of the same type. One of them was operated by setting the total combustion airstream with a hand-adjusted lever according to the instructions of the producer. The other was complemented by separate primary and secondary com-

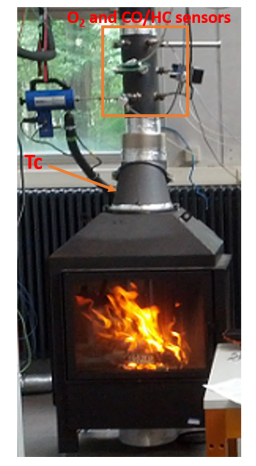

(a)

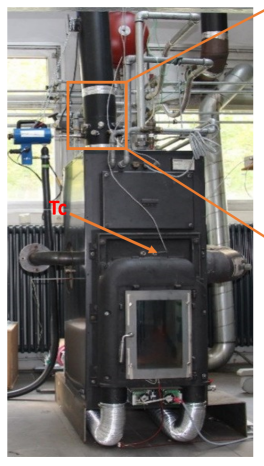

(b)

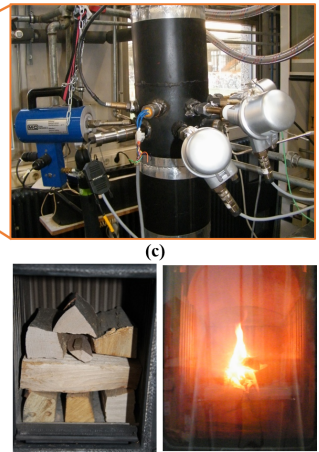

(d)

(e)
Figure 4. (a) The Varia $2 \mathrm{R}$ stove (Spartherm GmbH, Melle, Germany) used for the validation of the combustion process control. (b) The water-cooled SF10SK furnace (Brunner GmbH, Eggenfelden, Germany), and (c) the various types of $\mathrm{CO} / \mathrm{HC}$ sensors installed at the exhaust gas tube of the SF10SK fireplace. (d) The wood-stacking (e) upside-down combustion approach.

bustion airstream channels with motor-driven shutters to enable the operation with separate airstream control algorithms based on the Tc, ROC and $\mathrm{CO} / \mathrm{HC}$ signals of the corresponding in situ sensors. The airstreams were measured with standard mass flow sensors (HFM-7; Bosch, Stuttgart, Germany) and were adjusted to the desired flow by controlling the shutter position with separate nested control algorithms. This enables the later application of these airstream control algorithms to fireplaces with a natural chimney draught for which different draught conditions have to be expected. However, all experiments reported in this paper are conducted with a ventilation-controlled chimney draught in the ignition phase to guarantee that the chimney draught of the cold system is high enough. This was necessary due to some technical constraints related to the flow of the flue gas. For process control, a standard K-type thermocouple was installed at the post-combustion chamber for measuring the Tc. ROC was controlled at excess air conditions in the range of $5 \% \leq \mathrm{ROC} \leq 21 \%$ using a commercial oxygen sensor, LSU 4.9 (Bosch), and the signal representing the $\mathrm{CO} / \mathrm{HC}$ content was provided by a commercial CS10K mixed-potential gas sensor (Lamtec GmbH, Walldorf, Germany) operated at $640{ }^{\circ} \mathrm{C}$. Before conducting the firing experiments, the $\mathrm{CO} / \mathrm{HC}$ sensor was calibrated according to the routine described in Sect. 3.1. Both the ROC and the CO/HC sensor are installed at the exhaust gas pipe (Fig. 4a) together with an additional thermocouple for the monitoring of the flue gas temperature.

Another furnace, the SF10SK (Brunner GmbH, Eggenfelden, Germany; Fig. 4b), was used for the simultaneous evaluation of the different types of $\mathrm{CO} / \mathrm{HC}$ sensors (Fig. 4c) in the in situ flue gas operations. This fireplace has the advantage of a water-cooled periphery, which allows for secure operation at higher temperatures and attaining a better re- 


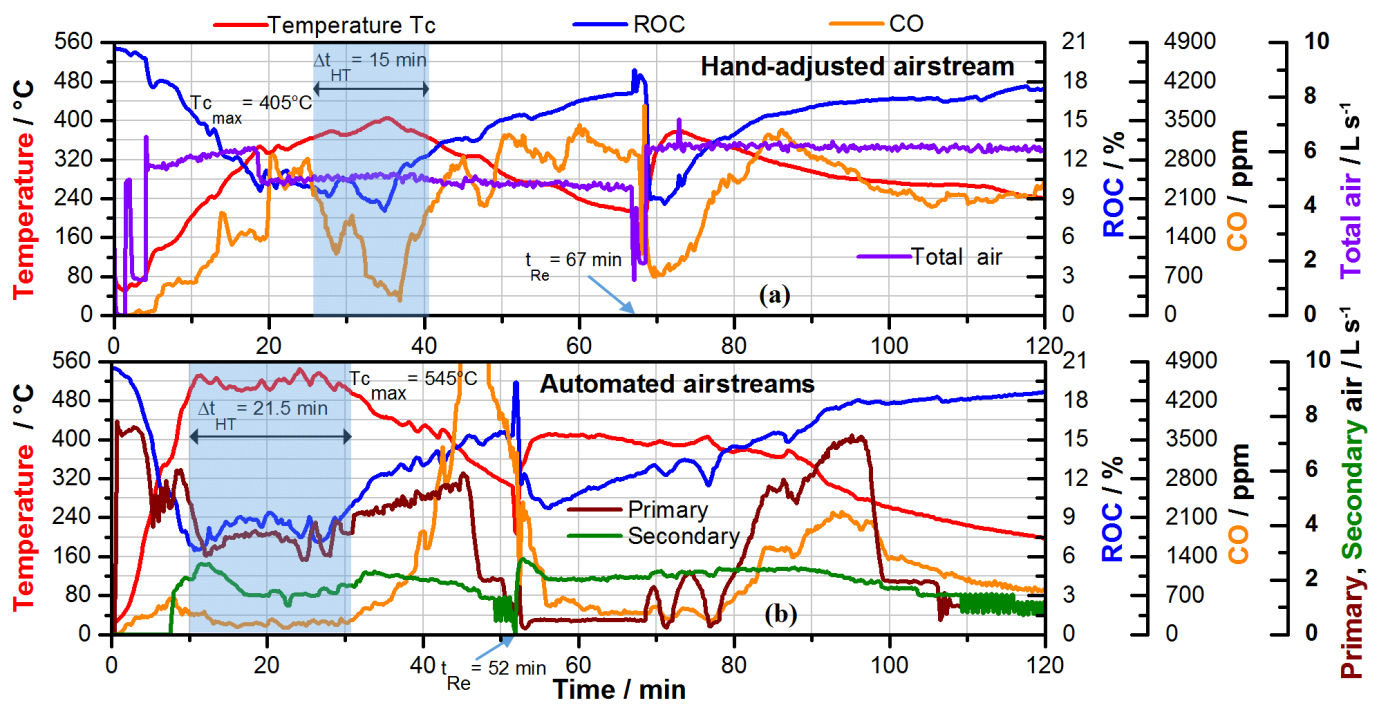

Figure 5. The differences in combustion airstreams and CO emissions (sampled with a high-temperature FTIR gas analysis system) of a hand-operated (a) and an automatically airstream-controlled (b) firewood combustion process in a Varia R fireplace. Due to the constructional design of the hand-operated fireplace, (a) only a total airstream could be sampled. The fireplace was reloaded with two additional logs on the glue bed at $t_{\mathrm{Re}}$. All CO concentration values are original data, i.e. not related to $13 \%$ ROC. Additionally, a catalyst in the experimental state (provided by the Deutsches Biomasseforschungszentrum (DBFZ), Leipzig, Germany) was used in the fireplace with automatic airstream control to study the improvement of the post combustion and the reduction in the emissions.

production of the firing experiments. The furnace was complemented with the same types of sensors for airstream control (HFM-7) and a thermocouple (K-type) for Tc sampling. ROC and $\mathrm{CO} / \mathrm{HC}$ were analyzed through the implementation of an LSU 4.9 and a CS10K $\left(T=760^{\circ} \mathrm{C}\right)$, respectively. The control algorithm was parameterized in several iterations referenced by the FTIR (GASMET Ansyco GmbH, Karlsruhe, Germany) gas analysis system for operation at highquality combustion conditions. In addition, this fireplace was equipped with an MO sensor array housed as illustrated in Fig. 2, a TGS823 MO sensor element and a CS1K mixedpotential sensor element.

In all the experiments conducted in both type of furnaces (Varia and SF10SK), dried firewood made of beech trees (with a guaranteed residual water content lower than 20\%) was used as fuel. In order to improve the reproducibility of the firing experiments, comparable total weights of the firewood and stacking pattern (Fig. 4d) were maintained. In all experiments, the ignition was started at the top of the firewood stack (upside-down combustion; Fig. 4e) using a commercial igniter. All $\mathrm{CO} / \mathrm{HC}$ sensor signals were simultaneously referenced by a high-temperature FTIR gas analysis system. The HT-FTIR conducts a continuous and detailed analysis of the IR-active exhaust gas components at time intervals of $10 \mathrm{~s}$ by extracting a well-defined flue gas stream of $5 \mathrm{~L} \mathrm{~min}^{-1}$.

\section{Results and discussions}

\subsection{Validation of control concept}

A comparative study of the emissions from the Varia $\mathrm{R}$ fireplaces with the hand-controlled and automatically controlled firing is represented in Fig. 5, focusing on only three process parameters: the Tc, ROC and CO concentration. In both experiments, the ignition is started at a cold-furnace state after the stacking of the logs according to the method described in Sect. 3. After the ignition of the hand-adjusted fireplace, Tc increases slowly and correlates inversely with ROC due to increasing combustion reaction kinetics (Fig. 5a). After having passed a temperature maximum, it decreases again because of the fuel consumption and the corresponding attenuation of the exothermic combustion rates. As already stated in Sect. 1, the phases of lower Tc are typically characterized by high emissions of un-combusted and partly combusted gas components due to the reduced combustion reaction kinetics. Correspondingly, there is an expected reduction of $c(\mathrm{CO})$ in the flue gas at the HT combustion phase; however, this decrease is not observed (Fig. 5a). Only for the short period during which the Tc approached $400{ }^{\circ} \mathrm{C}$ at time interval $25 \mathrm{~min} \leq t \leq 40 \mathrm{~min}$ is a clear decrease in $c(\mathrm{CO})$ observed. The reason for the relatively low $\mathrm{Tc}_{\max }$ is probably due to the too-high airstreams indicated by ROC $>8 \%$.

The firing process behaves substantially differently at controlled combustion airstream conditions (Fig. 5b). A temperature of about $530^{\circ} \mathrm{C}$ is reached notably faster $(\sim 11 \mathrm{~min})$ after ignition; correspondingly, the ROC clearly decreases 
Table 1. A comparison of CO emissions between an automated and a hand-adjusted Varia R stove.

\begin{tabular}{llrrr}
\hline & Unit & Automated & Hand-adjusted & Rel. value $(\%)$ \\
\hline $\mathrm{Tc}_{\max }$ & $\left({ }^{\circ} \mathrm{C}\right)$ & 545 & 405 & \\
$\mathrm{Tc}_{\max }-10 \%$ of $\mathrm{Tc}_{\max }$ & $\left({ }^{\circ} \mathrm{C}\right)$ & 490.5 & 364.5 & \\
Duration of HT phase $\left(t_{\mathrm{HT}}\right)$ & $(\mathrm{min})$ & 21.5 & 15 & \\
Total CO emissions in the HT phase & $(\mathrm{gm})$ & 1.954 & 6998 & 28 \\
Average CO emissions in the HT phase & $\left.(\mathrm{gm} \mathrm{min})^{-1}\right)$ & 0.091 & 0.466 & 19 \\
Duration of firing before reloading $\left(t_{\mathrm{Re}}\right)$ & $(\mathrm{min})$ & 51.5 & 66.8 & 56 \\
Total CO emissions & $(\mathrm{gm})$ & 24.49 & 45.32 & 70 \\
Average CO emissions before reloading & $\left.(\mathrm{gm} \mathrm{min})^{-1}\right)$ & 0.48 & 0.678 & \\
\hline
\end{tabular}

steeper with time and reaches a minimum value of about $6 \%$. Again, an inverse correlation of the ROC with Tc is observed over time due to the dependency of the combustion kinetics on Tc and the related oxygen consumption. As a consequence of the increased combustion kinetics, which may be further enhanced by an oxidation catalyst, the $\mathrm{CO}$ emission is remarkably low from ignition up to about the 35 th minute (Fig. 5b) until the temperature drops below $480^{\circ} \mathrm{C}$ (the beginning of the BOP). Beyond this time, the primary airstream is slowly increased to keep the combustion rate and corresponding Tc as high as possible before the software records $\mathrm{Tc}<360{ }^{\circ} \mathrm{C}$ and changes to the next phase, during which the airstreams are considerably reduced. Further, the $\mathrm{CO}$ concentration tremendously increases due to the too-low combustion kinetics. As observed in other experiments, due to the unfavourable collapse of the wood stack, part of the residual glue in the firing chamber is not well ventilated by the combustion air (an artefact due to (unfavourable) constructive properties of the furnace design).

After the reloading of firewood on the glue bed $\left(t_{\mathrm{Re}}\right.$ $\sim 67 \mathrm{~min}$ and $52 \mathrm{~min}$ for the hand- and automatically controlled stoves, respectively), the firing process is completely different compared to the previous process. This is because now the burning proceeds from the bottom of the wood ( $\mathrm{Vi}$ cente et al., 2015). With controlled airstreams well adapted to this new firing situation, the Tc can be maintained rather high (about $400^{\circ} \mathrm{C}$ ) and stable for a longer time, and the $\mathrm{CO}$ concentration is typically reduced to values below $700 \mathrm{ppm}$ for more than $20 \mathrm{~min}$ (Fig. 5b). However, in the case of the hand-controlled combustion, due to the short HT phase after reloading, the period of low-combustion emissions after reloading is quite short ( $\sim 6 \mathrm{~min}$; Fig. $5 \mathrm{a})$.

\subsubsection{Quantitative evaluation}

For a quantitative comparison of the total $\mathrm{CO}$ emitted in the hand-operated mode with the amount emitted in the automated firing mode, common standards for calculation had to be defined. The emissions (Table 1) are related to the HT phase but are also calculated for the total firing process from ignition up to the time when the reloading was started. For an estimation of the HT phase, we defined a time period during
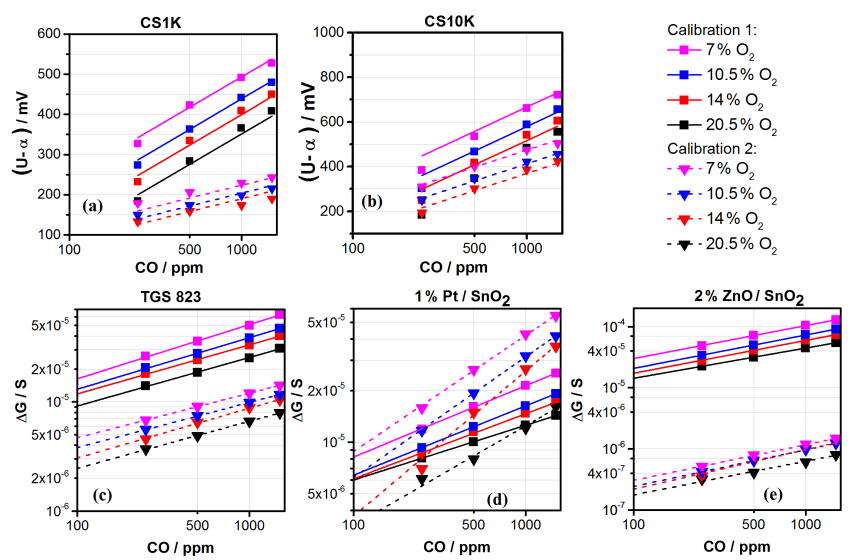

Figure 6. The responses of CS1K (a), CS10K (b), TGS823 (c), $1 \%$ $\mathrm{Pt} / \mathrm{SnO}_{2}$ (d) and $2 \% \mathrm{ZnO} / \mathrm{SnO}_{2}$ (e) to different $\mathrm{CO}$ and oxygen concentrations before (calibration 1) and after (calibration 2) the in situ operation in the firing experiments.

which the $\mathrm{Tc}$ varies in the range between $\mathrm{Tc}_{\max }$ and $\mathrm{Tc}_{\max }$ $-10 \%$ (Fig. 5). For the calculation of the relative amount of $\mathrm{CO}$ emissions, the $\mathrm{CO}$ concentration was multiplied by the total combustion gas stream at every point in time and then summed over the whole period of measurement. The latter operation is, of course, not suitable to calculate the absolute emissions because it does not consider the increase in the gas volume caused by the combustion process; however, it may be appropriate for a calculation of the relative emissions for comparison. The results summarized in Table 1 clearly show that the $\mathrm{Tc}_{\max }$ of the automated firing experiment is much higher than in the case of the hand-operated experiment. As visualized in Fig. 5, the HT time period is significantly longer. In spite of this, the total $\mathrm{CO}$ emissions calculated in the HT phases are only $28 \%$, and the average emissions are only $19 \%$ of those of the hand-operated furnace. When the emissions are calcuated over the whole period from firing to the time of reloading (Table 1), the results do not clearly favour the controlled operation. This may be due to the artefact mentioned above. 


\subsection{Evaluation of $\mathrm{CO} / \mathrm{HC}$ sensors}

As demonstrated in Sect. 4.1, the use of the $\mathrm{CO} / \mathrm{HC}$ sensors together with the continuous measurement of the ROC and $\mathrm{Tc}$ in low-power firing processes can clearly improve the control algorithms for the proper adjustment of the combustion airstreams at every instant of the batch firing process. However, there are two aspects which have to be considered in this context. The first aspect is the validity of the signals of the sensor elements with well-known cross-sensitivity to many combustible gas components and to ROC (Sect. 2) operated in the flue gas where these components vary largely over time. This is further discussed in Sects. 4.2.1. and 4.2.2. The second aspect is the long-term signal stability of the sensor elements, which is reported in Sect. 4.2.3. Both aspects were investigated through the simultaneous operation of several sensor elements in the exhaust gas of the automatically operated SF10SK fireplace.

\subsubsection{Sensitivity to model gases}

As an indication of sensitivity, the results of the calibration routine discussed in Sect. 3.1 are given in Fig. 6.

In Fig. 6, the initial calibration (calibration 1) before the firing experiments shows a clear sensitivity to $\mathrm{CO}$ and the applicability of Eqs. (1) and (2) (the solid lines). This is confirmed by the linearity of the signals on $c(\mathrm{CO})$ in a semilogarithmic and a full-logarithmic scale for the MP sensors (Fig. 6a, b) and MO sensors (Fig. 6c, d, e), respectively. As stated above, for both types of sensors investigated, the signals are strongly dependent on the oxygen background. While the MP sensors can be modelled to include the oxygen dependency directly $\left(\gamma_{i}\right)$, the MO-sensitive layers show a strong dependency of $\alpha_{i}$ on $c\left(\mathrm{O}_{2}\right)$ (offset in the logarithmic representation).

\subsection{2 $\mathrm{CO} / \mathrm{HC}$ sensor performance in the combustion process}

An overview of the signals of the different types of sensors installed in the SF10SK fireplace and the major IR-active flue gas components sampled simultaneously by the HT-FTIR analysis system during one typical batch firing process is given in Fig. 7. Figure 7a shows the variation in the Tc in the post-combustion chamber and in ROC with respect to time. As already discussed above, a steep decrease in ROC is observed with increasing temperature due to the higher reaction kinetics within the first $15 \mathrm{~min}$ (Fig. 7a). However, the Tc rises to much higher values $\left(700-800^{\circ} \mathrm{C}\right)$ in the HT combustion phase and is sustained over $30 \mathrm{~min}$.

The variation in the concentrations of the major gas components in the flue gas is illustrated in Fig. 7b. To get a linear correlation of the sensors responses to the gaseous emission concentrations, it is set to a logarithmic scale. During the IP, i.e. between 0 and the 15 th minute, the emissions are high. Relatively low emissions are expected at $\mathrm{Tc}$ above $700^{\circ} \mathrm{C}$, i.e

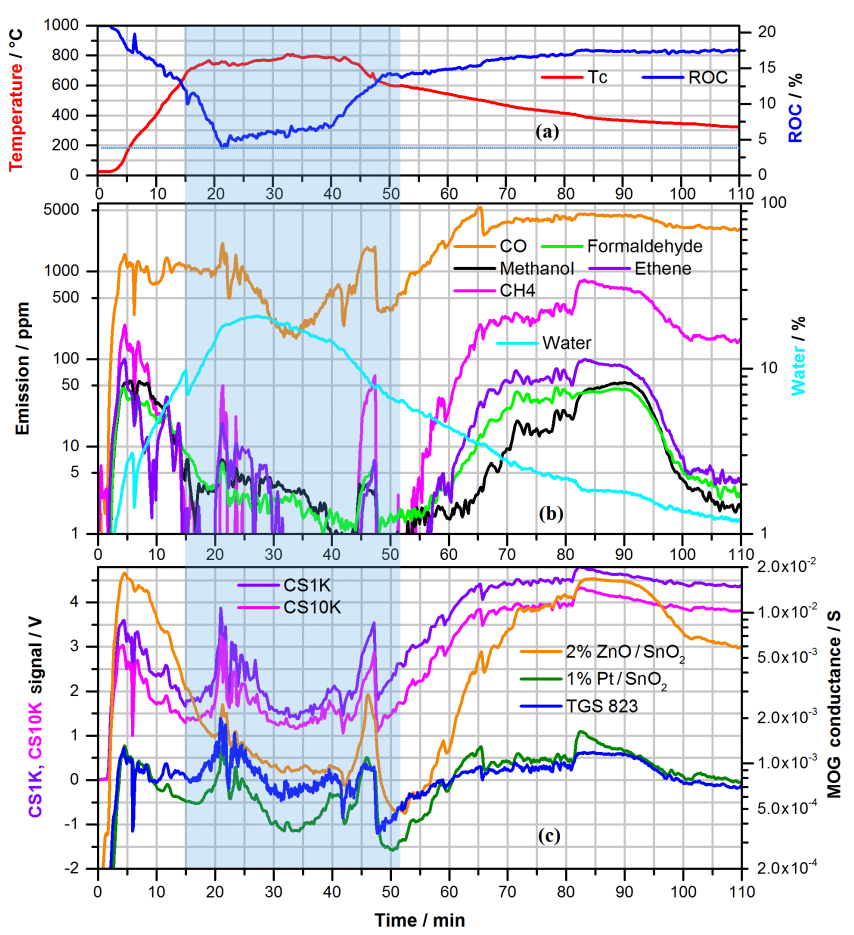

Figure 7. The batch firing process data over time recorded by operating the SF10SK fireplace. The transparent grey colouring indicates the high-temperature phase. (a) The variation in ROC with Tc. The horizontal blue dotted line (a) indicates the minimum ROC (about $4 \%$ ). (b) The FTIR signals related to the concentrations of $\mathrm{CO}, \mathrm{CH}_{4}$, formaldehyde, methanol, ethene and water vapour. (c) The sensor signals of the two CarboSen sensors with two layers from the sensor array at $1 \% \mathrm{Pt} / \mathrm{SnO}_{2}, 2 \% \mathrm{ZnO} / \mathrm{SnO}_{2}$ and TGS823.

Table 2. The Pearson correlation of the sensor signals with the main flue gas components as analyzed with the HT-FTIR gas analysis system (Fig. 7).

\begin{tabular}{lrrrrr}
\hline & $\mathrm{CO}$ & $\mathrm{CH}_{4}$ & Ethene & Methanol & Formaldehyde \\
\hline $\mathrm{CS} 1 \mathrm{~K}$ & 0.94 & 0.91 & 0.73 & 0.39 & 0.56 \\
$\mathrm{CS} 10 \mathrm{~K}$ & 0.93 & 0.9 & 0.74 & 0.42 & 0.57 \\
$\mathrm{TGS} 823$ & 0.52 & 0.4 & 0.59 & 0.65 & 0.62 \\
$1 \% \mathrm{Pt} / \mathrm{SnO}_{2}$ & 0.84 & 0.76 & 0.75 & 0.65 & 0.73 \\
$2 \% \mathrm{Zn} / \mathrm{SnO}_{2}$ & 0.75 & 0.87 & 0.83 & 0.8 & 0.86 \\
\hline
\end{tabular}

between the 15 th and the 45 th minute. However, in Fig. $7 b$, there is a clear indication that even at $\mathrm{Tc}>700^{\circ} \mathrm{C}$ the emissions are relatively high when the $\mathrm{ROC} \leq 6 \%$. This is assumed to be due to the imperfect admixing of the pyrolysis gases with the air in the post-combustion chamber. At ROC $\geq 6 \%$ and $\mathrm{Tc} \sim 800^{\circ} \mathrm{C}$, none of the gases detected by the HT-FTIR system exceed a concentration of $150 \mathrm{ppm}$ (related to $13 \%$ ROC) over a time period of about $10 \mathrm{~min}$. As soon as Tc decreases, the emissions of $\mathrm{CO}$ and hydrocarbons increase again. 
Concerning the $\mathrm{CO} / \mathrm{HC}$ sensor signals (Fig. 7c), several characteristic responses to the varying compositions of the flue gas are observed. Upon comparing the sensor signals with the calibration data discussed in Sect. 4.2.1, it is clear that the signal levels of all sensors are increased to a point that would not be representable with the calibration routine used. It is therefore necessary to express the signal behaviour observed in the calibration experiments in a scaled form that matches the signals in the firing experiment. In this work, this representation is called the $\mathrm{CO}_{\mathrm{e}}$ value, the determination of which is still a matter of investigation. To detail the influencing factors in the signal generation process of the given sensors, several highlights of the data shown in Fig. 7c will be discussed. The signals of CS1K and CS10K (Fig. 7c) coincide well with each other with an approximate constant signal offset, also seen in nearly equal correlation coefficients (Table 2). Both sensors are more sensitive to $\mathrm{CO}$ and methane than to the remaining hydrocarbons, as only minor signal rises are observed when high $\mathrm{HC}$ emissions are analyzed. But the signals are clearly enhanced in the HT combustion phase, i.e. at low ROC as expected according to Eq. (1).

The correlation of the behaviour of the sensor signal with the FTIR referencing signals is estimated by calculating the Pearson correlation coefficients (Mukaka, 2012) and listed in Table 2. The signal of the $1 \% \mathrm{Pt} / \mathrm{SnO}_{2}$-sensitive layer of the MO gas sensor array (Fig. 7c) follows the variation in the $\mathrm{CO}$ concentration over time and is also influenced by the variation in the hydrocarbon concentrations. This can be well observed at the time interval $60 \mathrm{~min} \leq t \leq 100 \mathrm{~min}$ and is confirmed by the correlation data (Table 2). In addition, the sensitivity is considerably enhanced in the HT combustion phase where the ROC is low and the water vapour concentration is very high. As already mentioned in Sect. 2 and confirmed in Sect. 4.2.1, the conductance of MO gas sensors is highly influenced by ROC and probably by water vapour as well. Further investigations will be necessary to analyze the contribution of both parameters, i.e. to what extent this cross-sensitivity can be compensated for by the ROC values, which are measured simultaneously. Similar behaviour is observed in the case of the TGS823 (Fig. 7c). In contrast, the second MO layer of the sensor array under investigation (Fig. 7c), $2 \% \mathrm{ZnO} / \mathrm{SnO}_{2}$, behaves clearly differently to the other $\mathrm{CO} / \mathrm{HC}$ sensors discussed above. This sensor shows a high signal dependency on the hydrocarbon concentrations (Table 2), while $\mathrm{CO}$ and water vapour play only a minor role in the signal formation. This is well observed in the initial $10 \mathrm{~min}$ after ignition and at the time interval $60 \mathrm{~min} \leq t \leq 100 \mathrm{~min}$. In both periods, the $\mathrm{HC}$ emissions are characteristically high. It is still open for investigation whether there is a generally high sensitivity of this sensing layer to all the hydrocarbons or only to a few individual components.

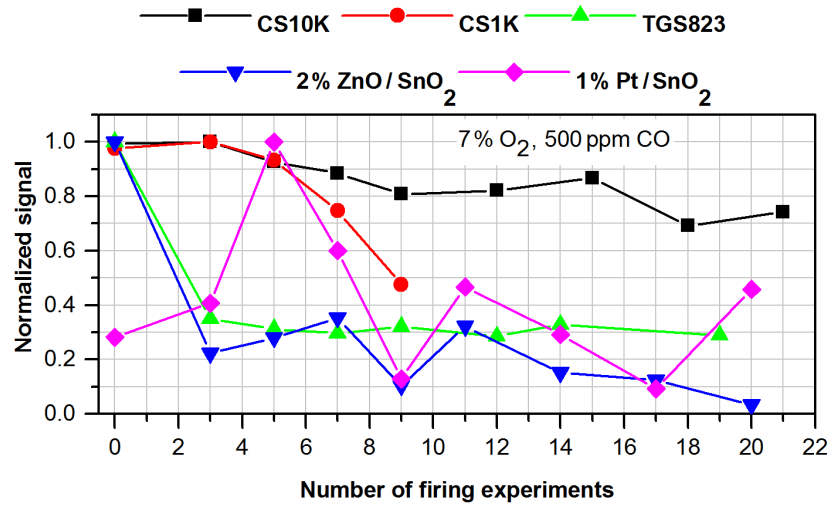

Figure 8. A comparison of the normalized sensor signals of the different sensors upon exposure to $500 \mathrm{ppm}$ of $\mathrm{CO}$ at a $7 \%$ oxygen concentration plotted vs. the number of firing experiments. The average gas exposure time of the sensors per firing experiment was about $4 \mathrm{~h}$.

\subsubsection{Investigation of sensor signal stability}

To assess the signal stability, the sensors were repeatedly tested in model gases at intervals after a certain number of firing experiments. Figure 6 shows the comparison of the initial (squares) and final (triangles) calibration. A decay in the signal is visible for all sensors except the $1 \% \mathrm{Pt} / \mathrm{SnO}_{2}$ gas sensor. But the signal of this sensing layer fluctuates over the time of operation in the flue gas (Fig. 8). In the case of the MP gas sensors (CS1K and CS10K), the sensor signal dropped after five firing experiments to about $92 \%$ of the original value. The sensor signal of the $\mathrm{CS} 1 \mathrm{~K}$, operated at $760^{\circ} \mathrm{C}$, continued to drop with continuing experiments, whereas the sensitivity loss of CS10K, operated at the same temperature, is clearly slower. After 21 firings, the signal seems to be more or less stable (Fig. 8). This shows that the long-term stability of these sensor elements has to be improved; however, the parameters which influence this essential property are actually still a matter of investigation.

Considering the TGS823, the relative conductance value dropped sharply to rather low values after three firing experiments and showed stable behaviour afterwards, even after 19 firing experiments. This might be due to the annihilation of the instable reaction sites during the first hours of operation in the flue gas. The $2 \% \mathrm{ZnO} / \mathrm{SnO}_{2} \mathrm{MO}$ layer shows a similar decrease in the signal (Fig. 8), but after the first drop there is still significant fluctuation and a slower decrease in the signal in the model gases is observed. This may indicate the irreversible or partly reversible blocking of the reaction sites at the gas-sensitive layer through gas adsorption. The exact reasons for this behaviour are not well understood and have to be further investigated. 


\section{Summary and conclusions}

Experiments with two identical fireplaces operated by hand and automated control concepts demonstrated that the use of the signals from in situ sensors for Tc, ROC and $\mathrm{CO} / \mathrm{HC}$ concentrations as inputs for a control algorithm for primary and secondary airstreams enables a considerable reduction in the emissions of $\mathrm{CO}$ and other unburned hydrocarbons by about $80 \%$ in phases during which the combustion temperature is high enough. In addition, such high-temperature phases can be prolonged through controlled operation. With this kind of control concept, $\mathrm{CO}$ concentrations lower than $150 \mathrm{ppm}$ (about $150 \mathrm{mg} \mathrm{m}^{-3}$ ) in the high-temperature phase of combustion are possible.

In this context, the suitability of different types of sensor elements for the in situ measurement of $\mathrm{CO} / \mathrm{HC}$ was the main focus of this investigation. All types of $\mathrm{CO} / \mathrm{HC}$ sensors are cross-sensitive to different flue gas components ( $\mathrm{CO}$, methane, formaldehyde) with individual specifications, and especially to ROC and water vapour. Signal changes influenced by varying oxygen concentrations can be well compensated for by the ROC sensor signal recorded simultaneously; however, there is no appropriate sensor for in situ water vapour monitoring available.

Among the sensors investigated, the signals of the CS1K and CS10K (mixed-potential type) are well correlated with the variations in $\mathrm{CO}$ emissions. The metal oxide sensor element $1 \% \mathrm{Pt} / \mathrm{SnO}_{2}$ shows even better correlation with $\mathrm{CO}$, but suffers from a higher influence of ROC and perhaps water vapour. The $2 \% \mathrm{ZnO} / \mathrm{SnO}_{2}$ metal oxide sensor element does not show significant cross-sensitivity to water vapour and ROC in the actual firing process. In contrast, the signals are well correlated with hydrocarbons rather than $\mathrm{CO}$. The TGS823 signal correlates with hydrocarbons as well as CO and shows a high cross-sensitivity to water vapour and ROC.

Considering stability, the sensitivity of all types of $\mathrm{CO} / \mathrm{HC}$ sensors decreased drastically with the operation time in the flue gas. Only a CS10K sensor operated at $760^{\circ} \mathrm{C}$ was found to be quite stable. After about $80 \mathrm{~h}$ of operation in the flue gas, it lost only about $25 \%$ of the original sensitivity. Looking to the family of metal oxide gas sensors, the sensitivity of $2 \% \mathrm{ZnO} / \mathrm{SnO}_{2}$ and TGS823 to the model gases was clearly reduced after the first firing experiments, then seems to be stabilized at a lower sensitivity level. Nevertheless, both are still sensitive enough for the online monitoring of the flue gas, even after about $70 \mathrm{~h}$ of operation in the flue gas. The $1 \% \mathrm{Pt} / \mathrm{SnO}_{2}$ layer, however, showed a highly fluctuating response in repeated tests in the model gases and still shows very sensitive behaviour in the flue gas. These instabilities will be a matter of research in the near future.

Another aspect is the reliability of these sensor signals considering the enormous variation in the flue gas composition. Using a single sensor element for $\mathrm{CO} / \mathrm{HC}$ monitoring and taking the sensor-specific cross-sensitivities into account, only a CO-equivalent flue gas concentration can be monitored, which reduces the quality of the combustion airstream control considerably. Further improvement can be expected through multivariate gas analysis by operating an array of sensing layers with different cross-sensitivities.

Data availability. Dataset for Figs. 5, 6, 7 and 8 is available at https://doi.org/10.5281/zenodo.582312 (Ojha et al., 2017).

Competing interests. The authors declare that they have no conflict of interest.

Acknowledgements. This work was funded by the programme "Optimierung der energetischen Biomassenutzung" of the Bundesministerium für Umwelt und Reaktorsicherheit and Fachagentur Nachwachsende Rohstoffe e.V. (Project-Id.: 22037214).

Edited by: J. Zosel

Reviewed by: two anonymous referees

\section{References}

Andersson, M., Pearce, R., and Spetz, A. L.: New generation SiC based field effect transistor gas sensors, Sensors and Actuators B, 179, 95-106, 2013.

Butschbach, P., Hammer, F., Kohler, H., Potreck, A., and Trautmann, T.: Extensive reduction of toxic gas emissions of firewoodfueled low power fireplaces by improved in situ gas sensorics and catalytic treatment of the exhaust gas, Sensors and Actuators B, 137, 32-41, 2009.

Comini, E., Faglia, G., and Sberveglieri, G., Solid State Gas Sensing, Springer Science \& Business Media, USA, 2009.

Eskilsson, D., Rönnbäck, M., Samuelsson, J., and Tullin, C.: Optimisation of efficiency and emissions in pellet burners, Biomass Bioenerg., 27, 541-546, 2004.

Frank, K., Magapu, V., Schindler, V., Kohler, H., Keller, H. B., and Seifert, R.: Chemical analysis with tin oxide gas sensors: choice of additives, method of operation and analysis of numerical signal, Sensor Letters, 6, 908-911, 2008.

Hahn, S. H., Barsan N., Weimer, U., Ejakov, S. G., Visser, J. H., and Soltis, R. E.: CO sensing with $\mathrm{SnO}_{2}$ thick film sensors: role of oxygen and water vapour, Thin Solid Films, 436, 17-24, 2003.

Illyaskutty, N., Knoblauch, J., Schwotzer, M., and Kohler, H: Thermally modulated multi sensor arrays of $\mathrm{SnO}_{2}$ /additive/electrode combinations for enhanced gas identification, Sensors and Actuators B, 217, 2-12, 2015.

Jalava, P. I., Salonen, R. O., Nuutinen, K., Pennanen, A. S., Happo, M. S., Tissari, J., Frey, A., Hillamo, R., Jokiniemi, J., and Hirvonen, M.: Effect of combustion condition on cytotoxic and inflammatory activity of residential wood combustion particles, Atmos. Environ., 44, 1691-1698, 2010.

Jerger, A., Kohler, H., Becker, F., Keller, H. B., and Seifert, R.: New applications of tin oxide gas sensors -II. Intelligent sensor system for reliable monitoring of ammonia leakages, Sensors and Actuators B, 81, 300-307, 2002. 
Knoblauch, J., Illyaskutty, N., and Kohler, H.: Early detection of fires in electrical installations by thermally modulated SnO2/additive-multi sensor arrays, Sensors and Actuators B, 217, 36-40, 2015.

Kohl, D.: Surface process in the detection of reducing gases with $\mathrm{SnO}_{2}$-based devices, Sensors and Actuators, 18, 71-113, 1989.

Kohler, H., Butschbach, P., Trautmann, T., and Belmir, H.: Wood energy for domestic heating: Extensive reduction of toxic gas and particulate matter emissions by optimized control of the firing process and use of gas sensors, edited by: Mastorakis, N. E., Demiralp, M., and Mladenov, V. M., WSEAS Press, ISBN: 978960-474-256-1, 492, 2010.

Kohler, H., Potreck, A., and Trautmann. T: Verfahren und Vorrichtung zur Verbrennung von Brennstoffen, Europäische Patentschrift EP, 2066972 B1, 2013.

Lenz, V. and Thrän, D.: Flexible Heat Provision from Biomass, in: Smart Bioenergy: Technologies and concept for more flexible bioenergy provision in future energy systems, edited by: Thrän, D., Springer International Publishing AG, Switzerland, 83-105, 2015.

Marutzki, R. and Seeger, K.: Energie aus Holz und anderer Biomasse, DRW Verlag, Weinbrenner GmbH \& Co., LeinfeldenEchterdingen, 1999.

Meyer, N. K.: Particulate, black carbon and organic emissions from small-scale residential wood combustion appliances in Switzerland, Biomass Bioenerg. 36, 31-42, 2012.

Miura, N., Sato, T., Angraini, S. A., Ikeda, H., and Zhuykov, S.: A review of mixed-potential type zirconia-based gas sensors, Ionics, 20, 901-925, https://doi.org/10.1007/s11581-014-1140$1,2014$.

Moos, R., Sahner, K., Fleisher, M., Guth, U., Barsan, N., and Weimar, U.: Solid State Gas Sensor Research in Germany - a Status Report, Sensors, 9, 4323-4365, https://doi.org/10.3390/s90604323, 2009.

Morrison, S. R.: Mechanism of semiconductor gas sensors operation, Sensors and Actuators, 11, 283-287, 1987.

Mukaka, M. M.: Statistics Corner: A guide to appropriate use of correlation coefficient in medical research, Malawi Medical Journal, 24, 69-71, 2012.
Nussbaumer, T.: Combustion and co-combustion of biomass: fundamentals, technologies and primary measures for emission reduction, Energ. Fuels, 17, 1510-1521, 2003.

Ojha, B., Illyaskutty, N., Knoblauch, J., Balachandran, M. R., and Kohler, H.: Dataset supplementing B. Ojha, N. Illyaskutty, J. Knoblauch, H. Kohler (2017): High temperature $\mathrm{CO} / \mathrm{HC}$ gas sensors to optimize firewood combustion in low power fireplaces, J. Sens. Sens. Syst., 6, 237-246, https://doi.org/10.5194/jsss-6-237-2017, 2017 [Data set], Zenodo, https://doi.org/10.5281/zenodo.582312, 2017.

Tapanainen, M., Jalava, P. I., Mäki-Paakkanen, J., Hakulinen, P., Happo, M. S., Lamberg, H., Ruusunen, J., Tissari, J., Nuutinen, K., Yli-Pirilä, P., Hillamo, Risto, Salonen, R. O., Jokiniemi, J., and Hirvonen, M.-R.: In vitro immunotoxic and genotoxic activities of particles emitted from two different small-scale wood combustion appliances, Atmos. Environ., 45, 7546-7554, 2011.

Tissari, J., Lyyränen, J., Hytönen, K., Sippula, O., Tapper, U., Frey, A., Saarnio, K., Pennanen, A. S., Hillamo, R., Salonen, R. O., Hirvonen, M.-R., and Jokiniemi, J.: Fine particle and gaseous emissions from normal and smouldering wood combustion in a conventional masonry heater, Atmos. Environ., 42, 7862-7873, 2008.

Vicente, E. D., Duarte, M. A., Calvo, A. I., Nunes, T. F., Tarelho, L., and Alves, C. A.: Emission of carbon monoxide, total hydrocarbons and particulate matter during wood combustion in a stove operating under distinct conditions, Fuel Process. Technol., 131, 182-192, 2015.

Wang, C., Yin, L., Zhang, L., Xiang, D., and, Gao, R.: Metal Oxide Gas Sensors: Sensitivity and Influencing Factors, Sensors, 10, 2088-2106, https://doi.org/10.3390/s100302088, 2010.

Wiegärtner, S., Hagen, G., Kita, J., Reitmeier, W., Hien, M., Grass, P., and Moos, R.: thermoelectric hydrocarbon sensor in thickfilm technology for on-board diagnostics of a diesel oxidation catalyst, Sensor and Actuators B, 214, 234-240, 2015.

Zhang, X., Kohler, H., Schwotzer, M., and Guth, U.: Mixedpotential gas sensor with PtAu-8YSZ sensing electrode: Electric potential difference measurements at isothermal and thermocyclic operation, Sensors and Actuators B: Chemical, 217, 107112, https://doi.org/10.1016/j.snb.2014.10.106, 2015. 